\title{
Method for wind turbine selection basing on in- field measurements
}

\author{
Katarzyna WOLNIEWICZ, Waldemar KUCZYŃSKI, Adam ZAGUBIEŃ
}

DOI: 10.30464/jmee.2019.3.1.77

Cite this article as:

Wolniewicz K., Kuczyński W., Zagubień A. Method for wind turbine selection basing on in-field measurements. Journal of Mechanical and Energy Engineering, Vol. 3(43), No. 1, 2019, pp. 77-84.

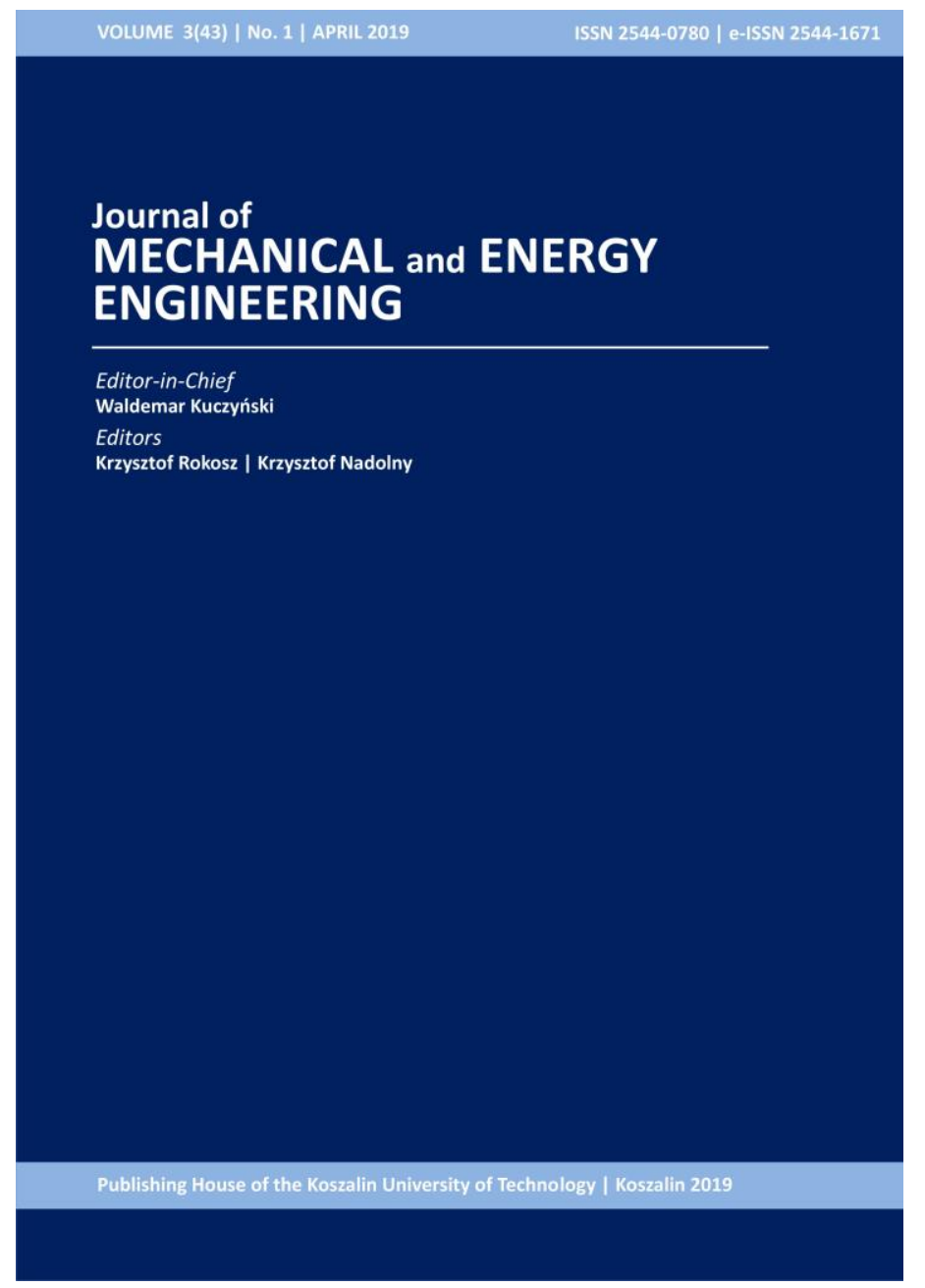

Journal of Mechanical and Energy
Engineering

Website: jmee.tu.koszalin.pl

ISSN (Print): 2544-0780

ISSN (Online): 2544-1671

Volume: 3(43)

Number: 1

Year: 2019

Pages: 77-84

\section{Article Info:}

Received 26 February 2019

Accepted 12 March 2019

\section{Open Access}

This article is distributed under the terms of the Creative Commons Attribution 4.0 (CC BY 4.0) International License (http://creativecommons.org/licenses/by/4.0/), which permits unrestricted use, distribution, and reproduction in any medium, provided you give appropriate credit to the original author(s) and the source, provide a link to the Creative Commons license, and indicate if changes were made. 


\title{
METHOD FOR WIND TURBINE SELECTION BASING ON IN-FIELD MEASUREMENTS
}

\author{
Katarzyna WOLNIEWICZ ${ }^{1 *}$, Waldemar KUCZYŃSKI ${ }^{2}$, Adam ZAGUBIEŃ ${ }^{3}$ \\ 1* Faculty of Mechanical Engineering, Department of Energetics, Koszalin University of Technology, \\ Racławicka 15-17, 75-620, Koszalin, Poland, e-mail: katarzyna.wolniewicz@gmail.com \\ 2 Faculty of Mechanical Engineering, Department of Energetics, Koszalin University of Technology, Poland \\ 3 Faculty of Civil Engineering, Environmental and Geodetic Sciences, Koszalin University of Technology, \\ Poland
}

(Received 26 February 2019, Accepted 12 March 2019)

\begin{abstract}
The following paper covers a method for wind turbine selection with a horizontal axis of rotation basing on real in-field measurements of wind conditions. The basic meteorological properties and characteristics obtained during measurement campaigns using necessary equipment as well as the used methodology are vital for successful investment in wind farm. The main goal of in-field investigation is to collect meteorological data using a measurement mast installed at the possible future wind farm location. The conducted measurement campaign provided wind directions, velocities and wind blast parameters. The measurements were conducted in the northern Poland using measuring system installed on 100 meter high mast. The system was equipped with all devices necessary to measure and record the basic wind parameters. The reliability of measurements was verified using statistical data for the Weitbull distribution and the wind rose. In this way, the energy potential of raw air stream that could possibly drive a wind turbine was determined. Among 6 pre-selected wind turbine types, the optimal one for a given location was proposed.
\end{abstract}

Keywords: wind turbines, wind power, wind conditions

\section{INTRODUCTION}

Rapid world-wide economic development of the XXI century resulted in significantly higher energy consumption in both domestic (rising population level and living standards) and industrial sectors (automated manufacturing). By 2030, it is estimated that the global energy demand may rise by another 50\% [1]. Therefore, proper functioning of the energy sector is the only way to provide rapid, but sustainable worldwide economic development. In Poland, $98 \%$ of energy comes from conventional energy carriers, with combined hard coal and lignite at $76 \%$, crude oil at $13 \%$ and natural gas at $9 \%$. However, the traditional energy carriers cause serious damage to biological life, ozone layer depletion as well as soil and air pollution [2]. Depletion of fossil fuels together with environmental protection cause encouraged the developed countries to employ an alternative state-ofthe-art technology based on natural resources of Earth,
Sun and gravitational forces of the planets [3]. The renewable sources of energy are as follow: solar radiation, tidal waves, ocean tides, biomass, wind, watercourses and geothermal. Because the renewables are practically inexhaustible, therefore it became very popular in the recent years. When it comes to wind energy, Poland exhibits a significant potential. The average wind speed in Poland varies from $2.8 \mathrm{~m} / \mathrm{s}$ during summer up to $3.8 \mathrm{~m} / \mathrm{s}$ in the winter. The best wind conditions occur at the coast of the Baltic Sea, around Sudovia and in Sub-Carpatian region. The development of wind energy sector strongly depends on availability of sites with sufficient wind potential. The wind speed is a crucial parameter that usually determines the decision about wind investment on a given area. Therefore, it is necessary to gather reliable data about wind speed at exactly the same height as the possible future turbine.

The optimal selection of wind turbine type, based on wind parameters at a given location, is the key to estimate the future electricity production. 
Measurements of wind parameters are necessary to asses a given location in terms of usefulness as a possible wind farm sitting. Complex planning of different aspects of measurement procedure can significantly reduce the risk and uncertainties during further stages of the wind turbine location design. It is necessary to properly select the instrumentation according to international measurement standards, but also to take into account the specifics of a given location. The measurements should take into account the landform, natural and infrastructural barriers, inclination and many other factors influencing the wind.

The following analysis consider 6 different wind turbine types with 100 meter high tower. The final decision was made basing on turbine parameters and wind data covering all four seasons.

\section{BASIC INFORMATION}

Statistical methods [4] describing wind speed variation used for energy potential assessment were based on the Weibull distribution [5]. It allowed to evaluate the wind resources using data specific for the location (time series of wind speed). The assessment is usually made basing on parameters estimated according to the Weibull distribution applied to the time series of wind speed for the investigated location and taking into account the theoretical wind power. It allows to determine the wind turbine power density necessary to estimate future amount of energy production [6]. The statistical methods are the most common ones, because they very accurately analyse the experimental data in terms of estimated energy generation. They allow to estimate the reliability of forecasts depending on the length of measurement period. Thus, it can foresee the probable fluctuations in energy generation during a month, season or entire year. The literature suggest that the statistical methods are helping to determine the energy potential of the wind as well as the energy generated [7], [8]. Usually part of the data is provided by the meteorological stations, including the wind speed. However, one should keep in mind that the time resolution is poor (usually several hours between the consecutive measurements) and at low altitude (usually 10 meters). Such data require extrapolation which results in lower reliability comparing to the dedicated equipment [9]. First of all, it does not provide the information how the wind speed varies with altitude. Moreover, it does not say anything about the landform roughness that strongly influences the calculation concerning wind turbines situated high above the ground level. The statistical methods are based on different types of distributions [10]. Apart from the most common 2parameter Weibull and single parameter Rayleigha distribution, there are also: general 3-parameter gamma, 2-parameter gamma, 2-parameter normal, 2- parameter logarithmic normal, reversed 2-parameter Gauss and 3-parameter beta distributions. Some particular cases require mixed approach, for example 2-term Weibull distributions with 5 parameters or Weibull mixed with normal distribution that has 4 parameters. It takes advantage of the density of probability function based on the maximum entropy (Shanonn maximum entropy) [11].

Depending on specific location, only one of the previously mentioned distribution will be the best fit to the measurement data. For the wind power purposes, it is very important to gather data from higher altitudes than the meteorological stations do. The meteorologists focus only on measurements of the atmosphere parameters that are important in terms of weather forecast. It is assumed that the minimal altitude for measurements should be around 20 to 30 meters, but much more useful are the measurements conducted on two or three different altitudes. If measurements from two different heights are available, for example 30 and 50 meters, then it is possible to model the wind speed profile, in example using an exponential curve. For data collected from 3 different altitudes it is possible to draw a logarithmic curve [12]. In such case, it is possible to relatively precise determine the wind speed at any height and as a result to obtain more accurate predictions concerning future electricity production. It is also possible to include additional data concerning the landform and take into account its influence on wind speed by introducing the landform roughness parameter. With increasing number of measurement points at different heights, the predictions become more and more accurate [13]. The data gathered is frequently used to forecast the wind speed, not only in terms of distribution and the average values, but also to predict short-term phenomena such as velocity fluctuations or even to find some statistical correlations between different measurement points [14]. Commonly known techniques of data presentation are the time series [15], Markow chain [16], or neural networks that recently became very popular [17].

\subsection{Measurement methodology}

The reference document describing the proper measurement methodology for the financial analysis of the wind farm project demanded by most of the banks was drafted the International Electrotechnical Commission with headquarters in Geneva, Switzerland. The guidelines are included in the standard IEC 61400-12-1 [18]. Appendix G of this document contains guidelines concerning proper installation of measurement instrumentation on the meteorological masts of pipe and lattice type. The guidelines included in standards IEC 61400-12-1 [18] and PN-EN 61400-12-1 [19], are internationally applied by many companies specialised in wind speed measurements. Only the measurements obtained using 
a high measurement mast or a tower can be classified as reliable measurements, and as such, they can be used as reference for any financial purposes during further stages of the project [20].

In order to be classified as possible to pay-off by any bank, the project should be based on an expertise concerning the wind condition. Such an expertise contains the measurement data from all the sensors, the shading effect and other analysis concerning the landform, measurement uncertainties, air density, wind direction distribution, turbine efficiency and many other. The bank expertise also covers the data that allows to assess the investment in terms of wind turbine selection, Weitbull distribution, wind direction distribution and the environmental impact [21].

\subsection{Landform and foundation}

The basic tools that determines the foundation of the future wind farms are the topography maps, landform roughness, natural and infrastructural barriers, complexity of wind conditions, selection of proper height and power of the wind turbines. When it comes to the landform types, there are only two [3]: plain with minor inclination or complex with inclination higher than $17^{\circ}$ and complicated topography. A field trip to the location of future wind farm can bring more reliable data about the landform like the photos, GPS records and the full image of all the nearby barriers. The distance between specific fixed barriers are measured and registered using the rangefinders. The barriers that can affect the wind are as follows: industrial buildings, households, forests, singular trees, chimneys, other wind turbines, observatory towers, telecommunication towers, hills, mountains, piles, bridges and many others.

\subsection{Delivery of wind condition measurement campaign}

In order to deliver a valid measurement campaign, it is necessary to employ high-end instrumentation to acquire, record and store the data as well as the proper measurement mast of tower. The nominal height of various measurement masts ranges from 2 up to 160 meters, depending on specific type. Usually, the mast is of a lattice or telescopic type. The proper quality of instrumentation affects the precision of wind condition measurements. The minimum period of a measurement campaign is 12 months. However, longer measurements can significantly increase the quality of the end-report.

The following article describes the measurements made for a location of future wind farm in situated in the northern Poland. The wind speed was measured at four different altitudes: 100, 98, 66 and 35 meters using 1 st class certified anemometers. Wind direction was tracked at two different heights: 100 and 66 meters. The temperature and humidity was recorded at two different altitudes: 98 and 3 meters. The measurement data was recorded digitally. Certificates of all the equipment were up-to-date.

\subsection{Validation of the experimental results}

Accuracy and correctness of the validation process as well as the in-depth analysis of the experimental data are the key elements that determine the usefulness of a given location in terms of its wind potential. The main goal of the end-report is to summarize the measurement period and to present the results in a graphical or tabular form. The analysis that summarize measurement period is conducted basing on the data collected from the measurement mast that cover different heights and instruments. Verification of experimental data aims to check the correct operation of all the instruments installed on the mast. The end-report is usually obtained using the register (windograf), that presents the data in a graphical from: monthly averaged wind speed, Weibull distribution, wind rose, temperature distribution and air density.

The following Figures presents the summary of selected data acquired during the measurement campaign at specific location in the northern Poland.

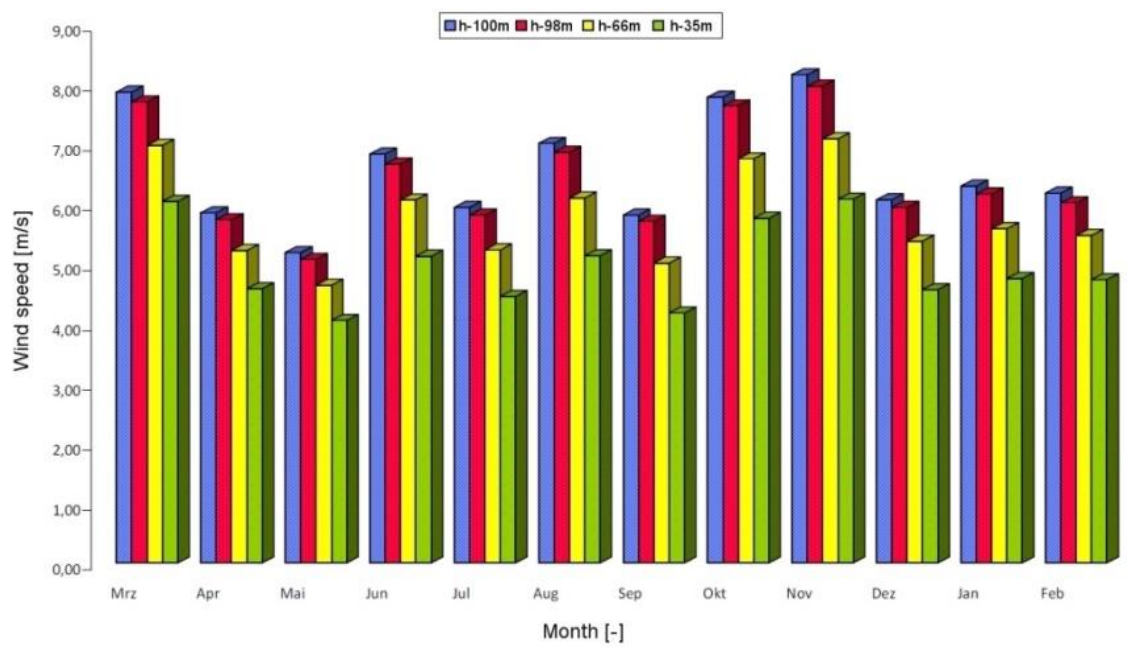

Fig. 1. Monthly average wind speed 


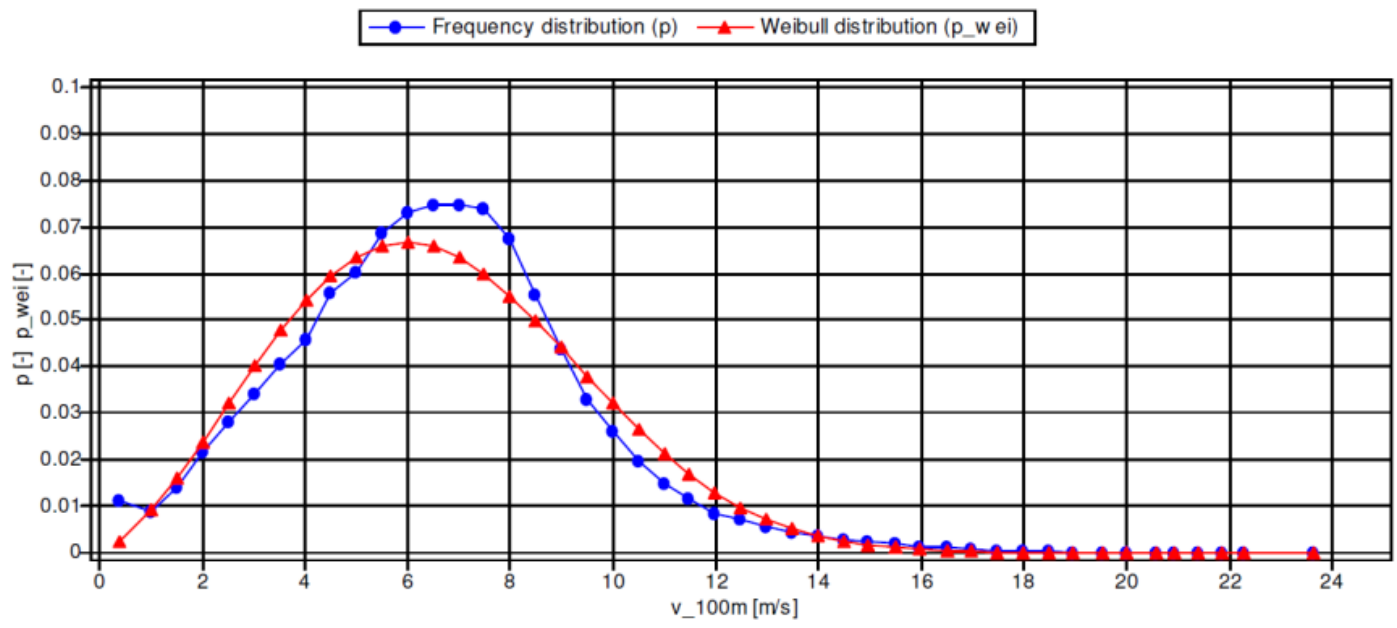

Fig. 2. Plot of measured wind speed distribution and fitted Weibull distribution for the anemometer at $100 \mathrm{~m}$ above ground level

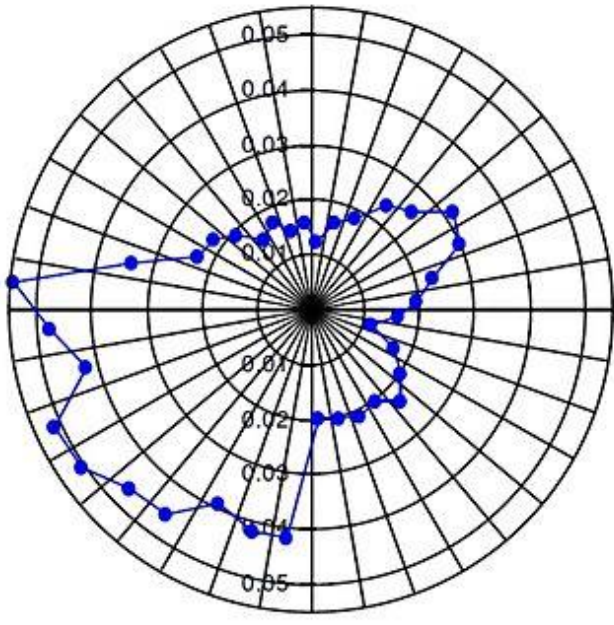

Frequency distribution $(p)$

Fig. 3. Wind direction distribution in the measurement period - wind rose

\section{WIND TURBINE SELECTION FOR THE EXPERIMENTALLY OBTAINED WIND CONDITIONS}

The experimentally obtained wind conditions were used during the turbine selection procedure for the investigated location. An important stage of this process was to properly determine the wind turbine type. There are many types of wind turbines available on the market and they are classified by many criteria, such as by-the-wind/against-the-wind, axis orientation: vertical/horizontal, output power: low $(50-250 \mathrm{~kW})$, medium $(250-750 \mathrm{~kW})$, high $(750-1500 \mathrm{~kW})$ and very high $(>1500 \mathrm{~kW})$. From the performance point of view, the important parameters are the impeller diameter and minimum operational wind speed. In the wind power sector, the most common solution are turbines with horizontal axis orientation. Table 1 presents the investigated turbine types.

The basic assumptions concerning the use of this type of turbines are presented in the section below.

Tab. 1. Parameters of investigated types of turbines

\begin{tabular}{ccccccc}
\hline $\begin{array}{c}\text { Vendor / } \\
\text { model }\end{array}$ & $\begin{array}{c}\text { Vestas / } \\
\text { V100 }\end{array}$ & Vestas / V90 & $\begin{array}{c}\text { General } \\
\text { Electric / } \\
\text { GE2.5 }\end{array}$ & $\begin{array}{c}\text { Fuhrlander / } \\
\text { W2E- } \\
100 / 2.55\end{array}$ & $\begin{array}{c}\text { Nordex / } \\
\text { N131/3000 }\end{array}$ & $\begin{array}{c}\text { Acciona / } \\
\text { AW116/3000 }\end{array}$ \\
\hline Power, [MW] & 2.0 & 2.0 & 2.5 & 2.5 & 3.0 & 3.0 \\
\hline $\begin{array}{c}\text { Impeller } \\
\text { diameter, }[\mathrm{m}]\end{array}$ & 100 & 90 & 88 & 100 & 131 & 116 \\
\hline
\end{tabular}




\subsection{Conversion of kinetic energy of moving air into electricity}

The atmosphere is subjected to various dynamic phenomena (changes in air temperature, wind direction and cloudiness) that result in movement of hot and cold air masses suspended above certain area. The key factor for this to occur is the pressure difference. Above the areas with different pressure the wind occurs. The higher pressure difference, the higher resulting wind speed [22]. The wind is pushing the turbine blade and as a result the impeller starts to spin. The wind speed downstream the turbine is lower than the upstream one. It is closely related with pressure difference in the vicinity of impeller (this difference is significantly higher upstream) and the pressure drop downstream (that at certain distance equals to atmospheric pressure). This phenomenon was discovered in 1920 by Betz [23]. According to law, it is theoretically impossible by a wind turbine to recover more than $59.3 \%$ of kinetic energy of the wind [24], [25]. The maximum power is obtained when the ratio of downstream $\left(v_{2}\right)$ to upstream $\left(v_{1}\right)$ wind speeds equals $\left(\frac{v_{2}}{v_{1}}\right)_{\text {opt }}=\frac{1}{3}$. Taking this into consideration, the maximum theoretical power of a wind turbine can be calculated according to the following formula:

$$
\begin{gathered}
P_{t h}=\pi \cdot r^{2} \cdot \frac{\rho}{4} \cdot\left(v_{1}+\frac{v_{1}}{3}\right) \cdot\left(v_{1}^{2}-\left(\frac{v_{1}}{3}\right)^{2}\right)= \\
\frac{8}{27} \cdot \pi \cdot \mathrm{r}^{2} \cdot \rho \cdot \mathrm{v}_{1}^{3} .
\end{gathered}
$$

In order to compare different technical solutions for wind turbine design, a standard theoretical power was introduced - $P_{u, t h}$, and it stands for power in the case of no resistance of the impeller against the air flow. The ratio between $P_{t h}$ and $P_{u, t h}$ stands for socalled theoretical wind utilisation coefficient:

$$
C_{p, \max }=\frac{P_{t h}}{P_{u, t h}}=\frac{\frac{8}{27} \cdot \pi \cdot r^{2} \cdot \rho \cdot v_{1}^{3}}{\frac{1}{2} \cdot \pi \cdot r^{2} \cdot \rho \cdot v_{1}^{3}}=\frac{16}{27}=0.5926 .
$$

In practice, this coefficient is calculated according to the following formula:

$$
C_{p}=\frac{1}{2} \cdot\left[1-\left(\frac{v_{2}}{v_{1}}\right)^{2}\right] \cdot\left(1+\frac{v_{2}}{v_{1}}\right) .
$$

The dependency between the $C_{p}$ coefficient on tipspeed-ratio $\lambda$ and the number of blades $Z$ for large and small turbines is presented in Fig.4. The tip-speedratio $\lambda$ stands for the ratio between the linear speed of blade tip and the wind speed, and can be calculated according to the following formula:

$$
\lambda=\frac{\Omega \cdot r}{c},
$$

$\Omega$ - angular velocity of turbine impeller, $\mathrm{rad} / \mathrm{s}$, calculated according to the following formula:

$$
\Omega=\frac{\pi \cdot n}{30} .
$$

Another important parameter in terms of wind turbine performance is the torque $M$. This physical quantity is also known as start-up momentum, because for a given turbine minimum wind speed the $M$ parameter has to overcome the resistance momentum. It applies to all possible weather conditions. The relation between the relative torque $C_{M}$ and the specific speed for different number of blades is presented in Fig.5.

The torque $M\left(\mathrm{~N}^{*} \mathrm{~m}\right)$ measured at impeller shaft should be calculated according to the following formula:

$$
M=C_{M} \cdot A \cdot \frac{\rho \cdot v^{2}}{2} \cdot r
$$

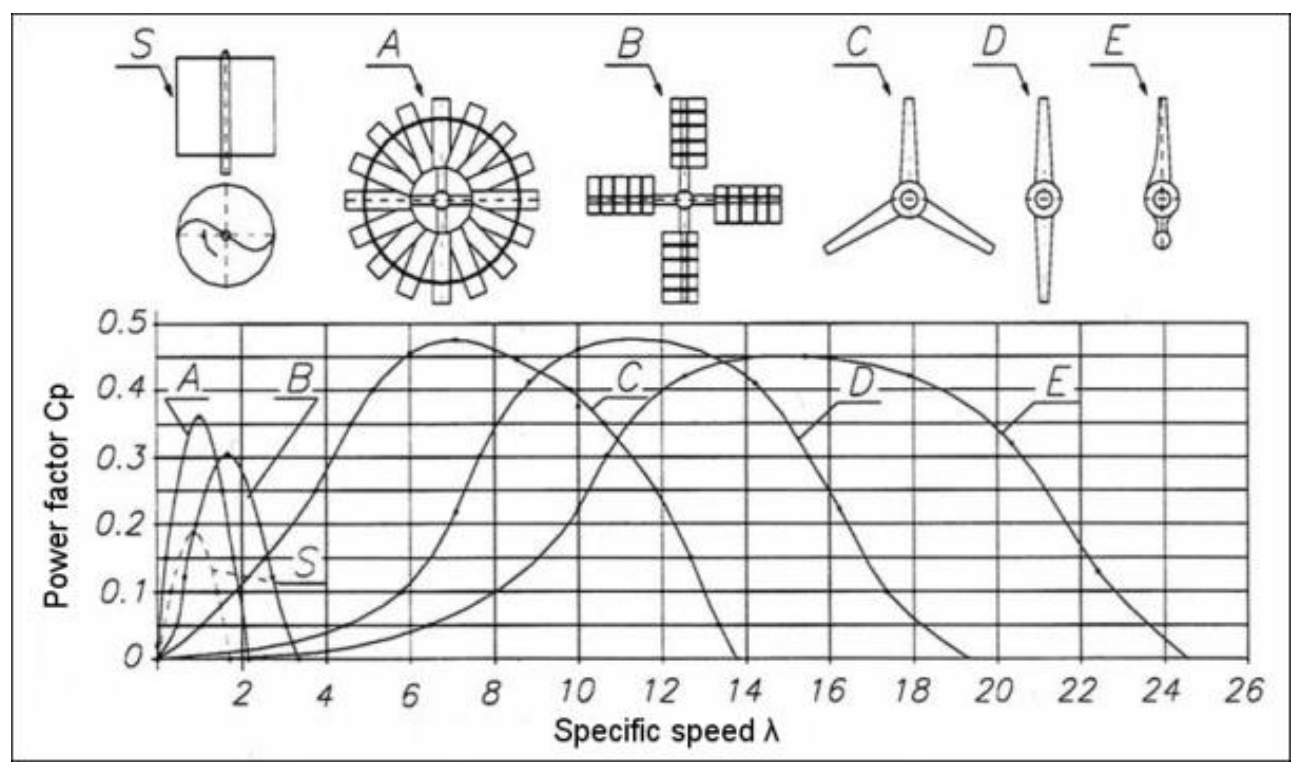

Fig. 4. Power coefficient $C_{p}$ as a function of tip-speed ration and number of blades [20] 


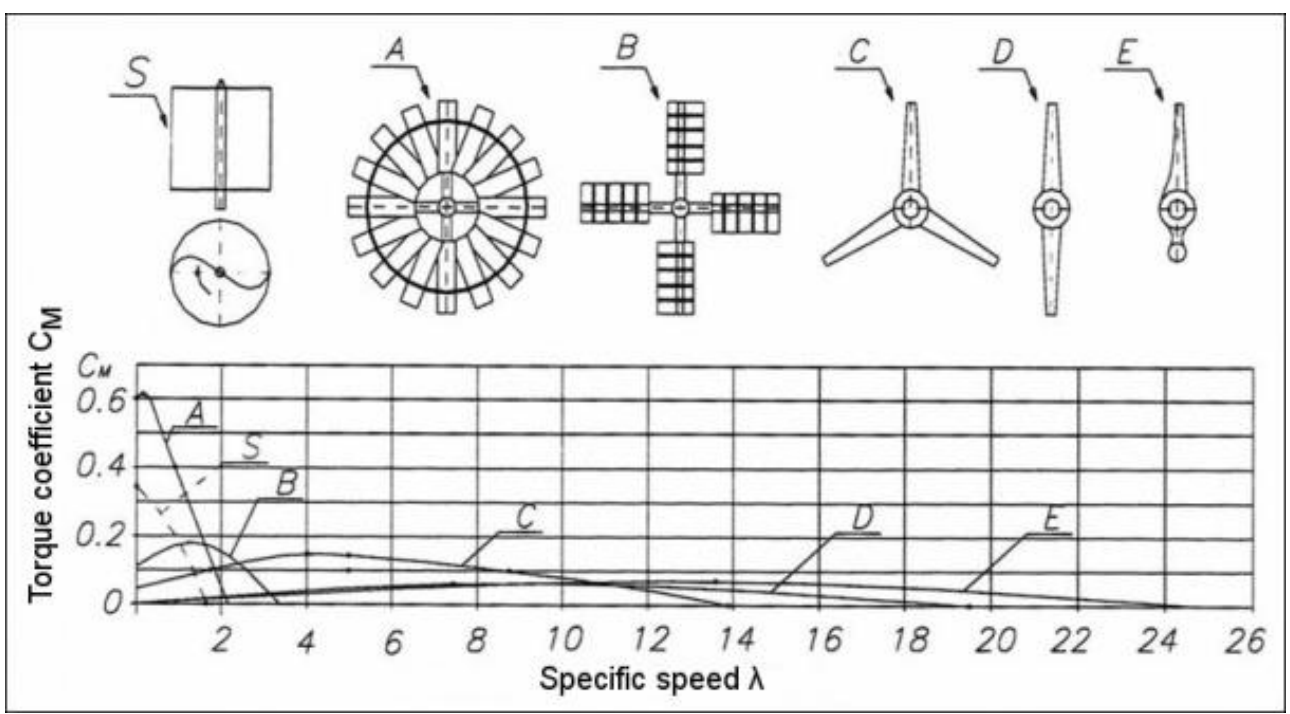

Fig. 5. Power coefficient $C_{M}$ as a function of tip-speed ratio and number of blades [20]

The value of the torque coefficient $C_{M}$ is important in the case of devices with small speed, thus demanding a high torque. This relation is characteristic for triple bladed wind turbines. During the calculations that serve the wind turbine selection process, it is assumed that overall performance takes into account the aerodynamic wind depletion coefficient, mechanical efficiency as well as generator efficiency, and equals between 23 and $46 \%$.

When the torque values is known, then it is possible to calculate the turbine mechanical power $P_{M}$ (W) according to the following formula:

$$
P_{M}=M \cdot \Omega \text {. }
$$

The impeller diameter is equally important in terms of proper wind turbine operation. This quantity can be determined using the power demand and the following formula:

$$
D=\sqrt{\frac{\tau \cdot P_{e l}}{\pi \cdot \rho \cdot C_{p} \cdot v^{3}}} .
$$

The impeller diameter is determined by rotational speed of turbine blades $(\mathrm{m} / \mathrm{s})$ :

$$
n=\frac{60 \cdot v_{\max }}{\pi \cdot D}
$$

It is also assumed that the height of the tower $H(\mathrm{~m})$ cannot exceed the following limit:

$$
H=H_{p}+0.9 \cdot D
$$

\subsection{Device selection basing on calculations of wind measurements}

Using the equation (7) it is possible to estimate the output power basing on the data collected during the measurement campaign. Basing on a yearlong wind measurements it was estimated that the year-average wind speed at the investigated location was $6.58 \mathrm{~m} / \mathrm{s}$. Assuming the total system performance $C_{p}=0.46$ (46\%), operation time (obtained experimentally) $\tau=7883 \mathrm{~h}$, axis of rotation at 100 and impeller diameter $100 \mathrm{~m}$, the system power can be estimated. By modifying the equation (7), the following formula for turbine power is derived:

$$
P_{e l}=\frac{D^{2} \cdot \pi \cdot C_{p} \cdot v^{3}}{\tau}=522.3(\mathrm{~kW}) .
$$

It means that each year (assuming $7883 \mathrm{~h}$ operation time) the turbine can produce 4,117,291 $\mathrm{kWh}$ of electricity, basing on the average wind condition at the $100 \mathrm{~m}$ altitude. The more detailed analysis for possible energy production on investigated location was conducted for six pre-selected types of wind turbines: Vestas V 100 and Vestas V 90 with the maximum power of $2 \mathrm{MW}$, General Electric GE2.5 and Fuhrlander W2E-100/2.55 with the maximum power of 2.5 MW as well as Nordex N131/3000 and Acciona AW 116/3000 with the maximum power of $3 \mathrm{MW}$.

Table 2 contains the number of hours per year with wind speed falling within specific range of $1 \mathrm{~m} / \mathrm{s}$ resolution. Basing on the productivity vs wind speed tables available for each turbine, the year energy production was determined of each of the turbines.

The investigated devices are mounted on 100 meter high towers. Each of the turbine exhibited sufficient performance in $\mathrm{kWh}$ that covered the demand calculated according to the formula (11). 
Tab. 2. Net energy produced by 6 different wind turbines

\begin{tabular}{|c|c|c|c|c|c|c|c|}
\hline \multirow[b]{2}{*}{$\begin{array}{l}\text { Wind speed } \\
\quad(100 \mathrm{~m}) \\
(\mathrm{m} / \mathrm{s})\end{array}$} & \multirow[b]{2}{*}{$\begin{array}{c}\text { Number of } \\
\text { hours per } \\
\text { year, (h) }\end{array}$} & \multicolumn{6}{|c|}{ Net Energy, (kWh) } \\
\hline & & $\begin{array}{l}\text { Vestas } \\
\text { V100 }\end{array}$ & Vestas V90 & $\begin{array}{c}\text { General } \\
\text { Electric } \\
\text { GE2.5 } \\
\end{array}$ & $\begin{array}{c}\text { Fuhrlander } \\
\text { W2E- } \\
100 / 2.55 \\
\end{array}$ & $\begin{array}{c}\text { Nordex } \\
\text { N131/3000 }\end{array}$ & $\begin{array}{c}\text { Acciona AW } \\
116 / 3000\end{array}$ \\
\hline 0.50 & 131.34 & - & - & - & - & - & - \\
\hline 1.50 & 258.84 & - & - & - & - & - & - \\
\hline 2.50 & 486.67 & - & - & - & - & - & - \\
\hline 3.50 & 695.00 & 43090 & 63245 & 36835 & 29885 & 72280 & 39615 \\
\hline 4.50 & 958.16 & 183967 & 191632 & 146598 & 89109 & 293197 & 208879 \\
\hline 5.50 & 1208.00 & 448168 & 437296 & 367232 & 276632 & 733256 & 560512 \\
\hline 6.50 & 1290.00 & 789480 & 758520 & 666930 & 559860 & 1331280 & 1025550 \\
\hline 7.50 & 1274.50 & 1217148 & 1133031 & 1019600 & 908719 & 2032828 & 1612243 \\
\hline 8.50 & 984.68 & 1376583 & 1236758 & 1138290 & 1069362 & 2215530 & 1893540 \\
\hline 9.50 & 585.00 & 1073475 & 957645 & 945360 & 913770 & 1602900 & 1505790 \\
\hline 10.50 & 344.00 & 681120 & 654976 & 708984 & 708984 & 1019960 & 1032000 \\
\hline 11.50 & 206.48 & 412754 & 410482 & 488532 & 497823 & 619440 & 619440 \\
\hline 12.50 & 124.01 & 248020 & 247896 & 307173 & 310025 & 372030 & 372030 \\
\hline 13.50 & 80.17 & 160340 & 160340 & 200265 & 200425 & 240510 & 240510 \\
\hline 14.50 & 56.00 & 112000 & 112000 & 140000 & 140000 & 168000 & 168000 \\
\hline 15.50 & 33.51 & 67020 & 67020 & 83775 & 83775 & 100530 & 100530 \\
\hline 16.50 & 19.83 & 39660 & 39660 & 49575 & 49575 & 59490 & 59490 \\
\hline 17.50 & 11.00 & 22000 & 22000 & 27500 & 27500 & 33000 & 33000 \\
\hline 18.50 & 5.50 & 11000 & 11000 & 13750 & 13750 & 16500 & 16500 \\
\hline 19.50 & 2.66 & 5320 & 5320 & 6650 & 6650 & 7980 & 7980 \\
\hline 20.50 & 3.00 & 6000 & 6000 & 7500 & 7500 & 9000 & 9000 \\
\hline 21.50 & 1.33 & 2660 & 2660 & 3325 & 3325 & 3990 & 3990 \\
\hline 22.50 & 0.17 & 340 & 340 & 425 & 425 & 510 & 510 \\
\hline \multicolumn{2}{|c|}{ Totally, (kWh) } & 6900143 & 6517821 & 6358299 & 5897094 & 10932210 & 9509108 \\
\hline
\end{tabular}

\section{CONCLUSIONS}

The following article presents the method for wind turbine selection basing on a real yearlong wind measurements. The wind measurements demonstrated the usefulness of investigated sitting location in terms of a future wind park investment. The presented process of turbine selection leads to an optimal choice of device for a given wind conditions. Six turbines with different power and impeller diameters were examined.

Wind parameters obtained with the measurement masts are the only reliable source of data. The financial analysis performed on their basis are important at the stage of ensuring the project financing and give an answer to the most important question asked by the investors: if and when the investment will pay-off?

To answer the question if the wind potential of a given location is optimally utilized, it is necessary to compare different turbines. As it turns out, the worst performance was obtained by the $2.5 \mathrm{MW}$ turbines. Due to the hourly distribution of specific average wind speeds, the second place was obtained by the $2 \mathrm{MW}$ turbines. As expected, the best performance was obtained by the 3.0 MW turbines.

The properly conducted measurement campaign allows to minimize the uncertainty of measurements and provide a high quality information about the wind conditions.

\section{Nomenclature}

\section{Symbols}

A $\quad-$ area covered by spinning impeller blades, $\mathrm{m}^{2}$

$C_{M} \quad-$ torque coefficient (Fig. 5)

$n \quad-$ impeller rotational speed, rpm

$r \quad-$ outer radius of turbine impeller, $\mathrm{m}$

$\rho \quad-$ air density, $\mathrm{kg} / \mathrm{m}^{3}$

$\tau \quad-$ number of turbine working hours per year

$v_{l} \quad-$ wind speed upstream the wind turbine, $\mathrm{m} / \mathrm{s}$

$v_{2} \quad-$ wind speed downstream the wind turbine, $\mathrm{m} / \mathrm{s}$

$v_{\max }-$ maximum linear speed of wind turbine blade

\section{References}

1. Mokrzycki E., Ney R., Siemek J. (2008). Global energy resources - conclusions for Poland. Energy Field, No 6, pp. 2-13. (in Polish)

2. Magiera J. (2010). Energy, man, environment. AGH University of Science and Technology, Krakow. (in Polish)

3. Zimny J. (2010). Renewable energy sources in lowenergy buildings. PGA AGH, Krakow-Warsaw. (in Polish)

4. Akpinar E., Akpinar S. (2005). An assessment on seasonal analysis of wind energy characteristics and wind turbine characteristics. Energy Conversion and Management, Vol. 46(11), pp. 1848-1867.

5. Celik A. (2003). Energy output estimation for smallscale wind power generators using Weibullrepresentative wind data. Journal of Wind Engineering and Industrial Aerodynamics, Vol. 91(5), pp. 693-707.

6. Jaramillo O., Borja M. (2004). Wind speed analysis in La Ventosa, Mexico: a bimodal probability distribution case. Renewable Energy, Vol. 29, pp. 1613-1630. 
7. Rehman S. (2004). Wind energy resources assessment for Yanbo, Saudi Arabia. Energy Conversion and Management, Vol. 45(13), pp. 2019-2032.

8. Akdag S., Dinler A. (2009). A new method to estimate Weibull parameters for wind energy applications. Energy Conversion and Management, Vol. 50(7), pp. 1761-1766.

9. Akdag S., Bagiorgas H., Mihalakakou G. (2010). Use of two-component Weibull mixtures in the analysis of wind speed in the Eastern Mediterranean. Applied Energy, Vol. 87(8), pp. 2566-2573.

10. Zhou J., Erdem E., Li G., Shi J. (2010). Comprehensive evaluation of wind speed distribution models: A case study for North Dakota sites. Energy Conversion and Management, Vol. 51, pp. 1449-1458.

11. Ramirez P., Carta J. A. (2006). The use of wind probability distributions derived from the maximum entropy principle in the analysis of wind energy. A case study. Energy Conversion and Management, Vol. 47(15), pp. 2564-2577.

12. Li M., Li X. (2005). Investigation of wind characteristics and assessment of wind energy potential for Waterloo region, Canada. Energy Conversion and Management, Vol. 46, pp. 3014-3033.

13. Tar K. (2008). Some statistical characteristics of monthly average wind speed at various heights. Renewable and Sustainable Energy Reviews, Vol. 12(6), pp. 1712-1724.

14. Morales J., Minguez R., Conejo A. (2010). A methodology to generate statistically dependent wind speed scenarios. Applied Energy, Vol. 87, pp. 843-855.

15. Cadenas E., Rivera W. (2007). Wind speed forecasting in the South Coast of Oaxaca, México. Renewable Energy, Vol. 32, pp. 2116-2128.

16. Sahin A., Sen Z. (2001). First-order Markov chain approach to wind speed modelling. Journal of Wind Engineering and Industrial Aerodynamics, Vol. 89, pp. 263-269.

17. Bechrakis D., Deane J., McKeogh E. (2004). Wind resource assessment of an area using short term data correlated to a long term data set. Solar Energy, Vol. 76(6), pp. 725-732.

18. IEC 61400-12-1:2005 (2005): Wind turbines: Part 21-1: Power performance of electricity producing wind turbines. IEC Genewa, Switzerland.

19. PN-EN 61400-12-1:2006 (2002): Wind turbines. Power performance measurements of electricity producing wind turbines. PKN Poland.

20. Jakubowski M., Mech Ł., Wolniewicz K. (2017). A methodology of wind turbines selection for the given wind conditions. Journal of Mechanical and Energy Engineering, Vol. 1(41), No 2, pp. 171-178.

21. Zagubien A. (2017). The Results of the Measurements and Analyses of Impact of Wind Farms on Acoustic Climate. Rocznik Ochrona Srodowiska, Vol. 19, pp. 527 539. (in Polish)

22. Zwoździak J., Zwoździak A., Szczurek A. (1998). Meteorology in the protection of the atmosphere. Oficyna Wydawnicza Politechniki Wrocławskiej, Wroclaw. (in Polish)

23. Betz A. (1920). Das Maximum der theoretisch möglichen Ausnutzung des Windes durch Windmotoren. Zeitschrift für das gesamte Turbinenwesen, No 26, pp. 307-309. (in German)

24. Okulov V., Sørensen J. (2008). Refined Betz limit for rotors with a finite number of blades. Wind Energy, Vol 11, pp. 415-426.

25. Vaz J., Wood D. (2016). Performance analysis of wind turbines at low tip-speed ratio using the Betz-Goldstein model. Energy Conversion and Management, Vol. 126, pp. 662-672.

\section{Biographical notes}

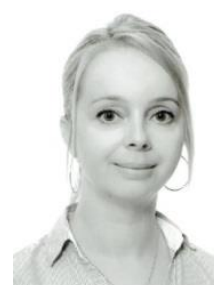

Katarzyna Wolniewicz has completed her MSc degree in Economic and also is $\mathrm{PhD}$ candidate at Faculty of Mechanical Engineering, Koszalin University of Technology. Her research interests are focused on infrasound, audible noise, fluctuations of acoustic pressure level in environment, multiscale analysis and modelling. She is an author and a co-author of over 10 scientific publications and oral presentations on international and national conferences.

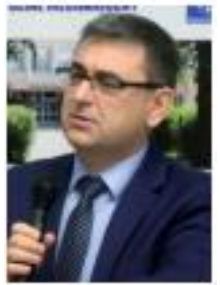

Waldemar Kuczynski is a graduate of the Koszalin University of Technology, Poland. Since 1999, he has been working as the Chair of Thermal Engineering and Refrigerating Engineering. In the year 2002, he was awarded the title of master of science in the field of machine construction and operation in the specialty of thermal engineering. In the years 2002 - 2007, he was a Ph.D. student at the Faculty of Mechanical Engineering of the Koszalin University of Technology. In the year 2008, under a project of the State Committee for Scientific Research, he defended his doctoral thesis entitled "Boiling Testing in Refrigerant Flow under the Conditions of Periodically Generated Disturbances" and in the year 2014 D.Sc. degree in Machinery Construction and Operation from Koszalin University of Technology. Since September 2008 he has been the head of the laboratory of the Chair of Thermal Engineering and Refrigerating Engineering and from 2016 he is also Deputy Dean of the Faculty of Mechanical Engineering of Koszalin University of Technology. He has authored and co-authored more than 100 articles and co-authored nine research projects (and the director of three). His chief interests focus on the issues of wave phenomena and instability during the condensation and boiling of refrigerants in conventional channels and in minichannels.

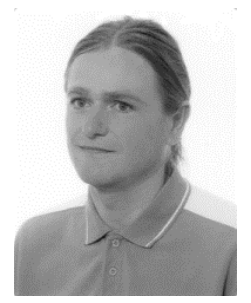

Adam Zagubień got a Ph.D. in Civil Engineering at Koszalin University of Technology (Poland). He is a lecturer at Faculty of Civil Engineering, Environmental and Geodetic Sciences, Koszalin University of Technology. His research interests are focused on infrasound, audible noise, fluctuations of acoustic pressure level in environment, multiscale analysis and modelling. He is an author and a co-author of over 50 scientific publications and oral presentations on international and national conferences. $\mathrm{He}$ is also an author and co-author of over 100 acoustic expertises for industry. He has been rewarded twice by the Chancellor of Koszalin University of Technology. 